\title{
The influence of annealing temperature and heating rate on thermoluminescence properties of nanocrystalline calcium borate powder
}

\author{
T. N. H. Tengku Kamarul Bahri*, R. Hussin, and N. E. Ahmad \\ Department of Physics, Faculty of Science, Universiti Teknologi Malaysia, 81310 Skudai, Johor Bahru, Malaysia
}

\begin{abstract}
We have reported the influence of annealing temperature and heating rate on thermoluminescence (TL) properties of nanocrystalline calcium borate, $\mathrm{CaB}_{2} \mathrm{O}_{4}$, powder synthesized by solution combustion method. Powder X-ray diffraction experiments were carried out on $\mathrm{CaB}_{2} \mathrm{O}_{4}$ to get the crystal phase and size. The samples were annealed using the TLD oven and exposed to cobalt-60 source. TL glow curves were measured and recorded using a Harshaw model 3500 TLD reader. The crystal phase confirmed one major phase of $\mathrm{CaB}_{2} \mathrm{O}_{4}$ with $27 \mathrm{~nm}$ in size. $\mathrm{CaB}_{2} \mathrm{O}_{4}$ has a simple glow curve with only one and a well defined peak at around $150{ }^{\circ} \mathrm{C}$. TL intensity was higher after annealing the material before irradiation which indicated the importance of annealing. It was found that an annealing temperature at $300{ }^{\circ} \mathrm{C}$ for one hour and the heating rate of $10^{\circ} \mathrm{C} \mathrm{s}^{-1}$ was the best procedure to produce high TL intensity.
\end{abstract}

\section{Introduction}

Thermoluminescent (TL) dosimetry is used for radiation protection purposes and clinical uses such as for measuring absorbed dose to patient in diagnostic radiology and radiotherapy. Currently, in Malaysia there are 25 radiotherapy centres comprising 7 government hospitals and 18 private medical centres, serving a population of 31.7 million people in 2016. As a member of a state of the International Atomic Energy Agency (IAEA), Malaysia has participated in a project called "IAEA/WHO Thermoluminesence Dosimeter (TLD) Postal Audit Program" [1]. The objective was to provide a quality audit on the dose delivered by megavoltage X-ray teletherapy units for radiotherapy centres worldwide. In Malaysia, total numbers of cobalt-60 and high energy photon beams that have been audited within these years were 19 and 13 units, respectively. TLD-100 (LiF: Mg, Ti) powder was used as a transfer detector in the IAEA and WHO TLD postal dose quality audit because of its good physical aspects including size and tissue equivalent composition and eases of transportation. However, TLD-100 has several notable drawbacks such as being hygroscopic [2]. Also, challenges and requirements of thermoluminescent materials were low cost production and a simple glow curve structure which eliminates the need for complicated annealing regimes as TLD-100 has a complicated glow curve [3]. With these restrictions in mind and the increasing use of radiation in the processes associated with medical and industrial applications have motivated research on new materials with adequate dosimetric properties.

Nanocrystalline from borate compound has revealed that they include some outstanding characteristics such as high sensitivity and applicable to a linear dose response over a wide range of absorbed dose [4-7]. Calcium borate, $\mathrm{CaB}_{2} \mathrm{O}_{4}$ is one of the widely studied oxide materials because of its excellent structural and optical properties. This compound with a bone effective atomic number $\left(Z_{\text {eff }} \sim 12.5\right)$ can be counted as a promising material for the future of personal and environmental applications [8]. Gowda et al. [9] had mentioned in his report that radiation interactive characteristics of mixture or compounds that were similar to bone, soft tissue or any other body constituents can be identified for dosimetric purposes. $\mathrm{CaB}_{2} \mathrm{O}_{4}$ polycrystalline present a good chemical stability due to their very low hygroscopic nature [10] and linear response with X-ray dose ranges 1 to $1000 \mathrm{mGy}$ and 1 to $10,000 \mathrm{mGy}$, respectively [11]. The solution combustion method is the among the most popular techniques of production nanocrystals, simple and rapid process. The dissolution process enables the amount of each component to be controlled accurately and uniformly mixed in liquid phase, while the combustion part is a time and energy saving method especially for the preparation of complex oxides. Also, the crystal powder of the solution combustion method is mostly homogeneous, more pure and low cost production than the crystal powder obtained via other conventional solid-state methods [12]. The aim of the study herein was to determine the influence of annealing temperature and heating rate on TL properties based on nanocrystalline $\mathrm{CaB}_{2} \mathrm{O}_{4}$ powder prepared by solution combustion method.

\footnotetext{
* Corresponding author: tnhidayah2@gmail.com
} 


\section{Experimental}

\subsection{Synthesis}

$\mathrm{CaB}_{2} \mathrm{O}_{4}$ was synthesized using the solution combustion method taking into consideration the following chemical reactions:

$$
\mathrm{Ca}\left(\mathrm{NO}_{3}\right)_{2} .4 \mathrm{H}_{2} \mathrm{O}+4 \mathrm{H}_{3} \mathrm{BO}_{3}+7 \mathrm{CH}_{4} \mathrm{~N}_{2} \mathrm{O}+7 \mathrm{NH}_{4} \mathrm{NO}_{3}: \mathrm{CaB}_{2} \mathrm{O}_{4}
$$

The starting raw materials used include various proportions of analytical pure grade calcium nitrate, tetrahydrate, $\left(\mathrm{Ca}\left(\mathrm{NO}_{3}\right)_{2} .4 \mathrm{H}_{2} \mathrm{O}, 99 \%\right.$, Merck $\mathrm{KGaA}$, Germany), boric acid $\left(\mathrm{H}_{3} \mathrm{BO}_{3}, 99.5 \%\right.$, Merck $\mathrm{KGaA}$, Germany), urea $\left(\mathrm{CH}_{4} \mathrm{~N}_{2} \mathrm{O}, 98 \%\right.$, Sigma-Aldrich, Missouri) and ammonium nitrate $\left(\mathrm{NH}_{4} \mathrm{NO}_{3}, 95 \%\right.$, Merck KGaA, Germany). $\mathrm{CH}_{4} \mathrm{~N}_{2} \mathrm{O}$ functioned as fuel for combustion as it was the most popular and attractive fuels for producing highly uniform, complex oxide ceramic powders with precisely controlled stoichiometry [13]. Meanwhile, $\mathrm{NH}_{4} \mathrm{NO}_{3}$ was used as oxidizer because of the highly porous nanocrystalline powder obtained. Porous structure played a key role in decreasing agglomeration, increasing surface area and improving sintering behavior [14]. The raw materials were weighed according to the chemical composition of $\mathrm{CaB}_{2} \mathrm{O}_{4}$ and put in a $100 \mathrm{ml}$ beaker. $15 \mathrm{ml}$ of deionized water was added and thoroughly mixed using a magnetic stirrer for 20 minutes without heating to obtain a uniform solution. The solutions were then poured into porcelain crucible and placed in a muffle furnace pre-heated at $500{ }^{\circ} \mathrm{C}$. Initially, the solution boiled and underwent dehydration, followed by decomposition releasing large amounts of gases (oxides of carbon, nitrogen and ammonia). Then, spontaneous ignition and smoldering occurred which gradually led to an explosion with enormous swelling. The entire combustion process was in 15 minutes. When taken out of the muffle furnace and cooled down, white voluminous foamy porous was obtained, which was easily grinded using mortar and pestle to obtain the synthesized fine, white powders $\mathrm{CaB}_{2} \mathrm{O}_{4}$. Following the combustion, to remove the deposited carbon and the unreacted organic residues and also to enhance crytallinity of pure compound $\mathrm{CaB}_{2} \mathrm{O}_{4}$, the heating process was carried out in temperature of $900{ }^{\circ} \mathrm{C}$ for a fixed time of one hour. Thus, the as-synthesized powders were placed into alumina crucible and heated in a furnace with temperature $900{ }^{\circ} \mathrm{C}$. Then, the powder samples were taken out of the furnace and left to cool down at room temperature.

\subsection{Characterization}

In order to check the formation of the samples, X-ray diffraction (XRD) analysis was carried out. The powder samples were scanned by mean of X-ray diffraction using Siemens Diffractometer D5000, with CuK $\alpha$ radiation operating at $40 \mathrm{kV}, 30 \mathrm{~mA}$ and use Bragg-Brentano geometry at room temperature, $25^{\circ} \mathrm{C}$. The diffraction pattern was measured in

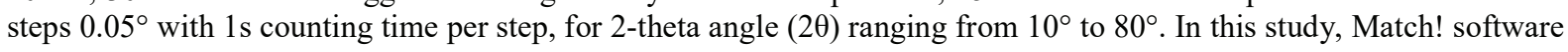
was used for phase identification from powder diffraction data. It compares the diffraction pattern of the sample obtained to a database containing reference patterns in order to identify the phases which are present. The crystalline size, $d_{X R D}$ can be determined from the most intense and sharp diffraction peak by using Debye-Scherrer formula, with assuming that the particles are stress free [15], as given below:

$$
d_{X R D}=\frac{0.9 \lambda}{\beta \cos \theta}
$$

where $d_{X R D}$ is average crystalline size, $\lambda$ is incident wavelength, $\theta$ is the Bragg angle and $\beta$ is the diffracted full width at half maximum (in radians), caused by crystals.

Before studying the TL properties of samples, the nanocrystalline $\mathrm{CaB}_{2} \mathrm{O}_{4}$ powders were initially annealed using the TLD oven type LAB-01/400. This annealing procedure consists of changing the temperature, step by step, at a constant annealing time and heating rate. The temperatures used were $100{ }^{\circ} \mathrm{C}, 200{ }^{\circ} \mathrm{C}, 300{ }^{\circ} \mathrm{C}$ and $400{ }^{\circ} \mathrm{C}$. The annealing time was kept constant at one hour for each temperature with heating rate $10^{\circ} \mathrm{C} \mathrm{s}^{-1}$. After annealing, the sample powders were loaded into small black plastic capsules. This capsule was made of opaque polyethylene capsules (IAEA type) of $3 \mathrm{~mm}$ diameter, $15 \mathrm{~mm}$ length and with $1 \mathrm{~mm}$ thick walls. Each capsule contains about $100 \mathrm{mg}$ of TLD-powder. These capsules were then kept in the closed cabinet to avoid direct sunlight and ultraviolet radiation that may contribute to the development of background signal. Temperature within the TLD storage room also was controlled for not higher than $30{ }^{\circ} \mathrm{C}$ to maintain the stability of the parameters.

Irradiation was performed using a cobalt-60 source (Gammacell 220 Excel, MDS Nordion, Ottawa, Canada) at dose $100 \mathrm{~Gy}$ at room temperature. The set up for beam field size and standard source-surface distance (SSD) that were used was $10 \times 10 \mathrm{~cm}^{2}$ and $100 \mathrm{~cm}$, respectively. After 24 hours irradiation, powder samples were read using a Harshaw model 3500 TLD reader with the Windows Radiation Evaluation and Management System (WinREMS) software. Powder dispenser was used to aid in dispensing accurate amounts of dosimetric powders, taking consistent delivery of a set amount $15 \mathrm{mg}$ to the planchet of the 3500 reader. The process was performed with care to reduce any loss of powder during dispensing. 
To read TL material, a time temperature profile (TTP) must be set up. TTP is the temperature to which the TL material is heated as a function of time. It is defined in three segments: Preheat, Acquisition, and Anneal. Preheat establishes a common starting point for all dosimeters in a group and may be used to eliminate the fast-fading low temperature peaks. Acquisition is the segment during which the dosimetric data are acquired and the glow curve is generated. The Anneal segment is used to hold the dosimeter at a high temperature to ensure that the entire TL signal is removed. Data obtained transmits to WinREMS in the form of 200 response points forming a glow curve. The glow curve generated plots the counts versus temperature automatically and the calculation formula in Eq. (2b) needs to be set in Excel in order to convert from counts to nanoamperes.

$$
Q(C) / t(s)=I(A)
$$

This can be written as

$$
\frac{\text { counts }}{16000 \text { counts }}(n C) / \frac{t_{a c q}(s)}{200 \text { glow curve acquisition points }}=I(n A)
$$

where $Q$ is the electrical charge converted from the light captured by the photomultiplier (PMT) that is collected from each sample in 16000 data points along. The $t$ is the time when the dosimetric data is acquired in 200 channels and $I$ is the electric current produced. The acquisition time in seconds $\left(t_{a c q}\right)$ can be found on the TTP that was created. The total amount of electric current produced and area integral under the glow curves yields the TLD reading (or TL response) signifies the radiation energy deposited and used for measuring the TL intensities. Usually, in units of micro coulombs since current multiplied by time equals charge and coulombs is the unit of charge. In this study, an average TL signal from a set of six readings was calculated and were normalized to unit mass (g) to obtain a net TL signal. The results had to be normalized in order to compensate differences of masses shapes and size of the samples.

\section{Results and discussion}

\subsection{Crystalline phase and size}

Fig. 1 shows the XRD pattern of $\mathrm{CaB}_{2} \mathrm{O}_{4}$ after heat treatment at temperature $900{ }^{\circ} \mathrm{C}$ for 1 hour. The major crystalline phase of $\mathrm{CaB}_{2} \mathrm{O}_{4}$ is formed as the products of the nitridation reaction. This is in good agreement with the reference database from the Joint Committee on Powder Diffraction Standards (JCPDF) card number 75-0640. The obtained product has orthorhombic lattice with the lattice parameters $\mathrm{a}=6.19 \AA, \mathrm{b}=11.60 \AA$, and $\mathrm{c}=4.28 \AA$. XRD pattern reported by Huang et al. [16] also indicated the pure phase of $\mathrm{CaB}_{2} \mathrm{O}_{4}$ at $900{ }^{\circ} \mathrm{C}$. Meanwhile, Yang et al. [17] reported that heating crystallized within the temperature region of $800{ }^{\circ} \mathrm{C}$ to $900{ }^{\circ} \mathrm{C}$ and mostly in two stages, corresponding to calcium borate and calcium silicate crystallization. The crystalline size was estimated from most intense and sharp diffraction peak at $29.6^{\circ}$ by using Eq. (1), which was approximately $27 \mathrm{~nm}$ in size.

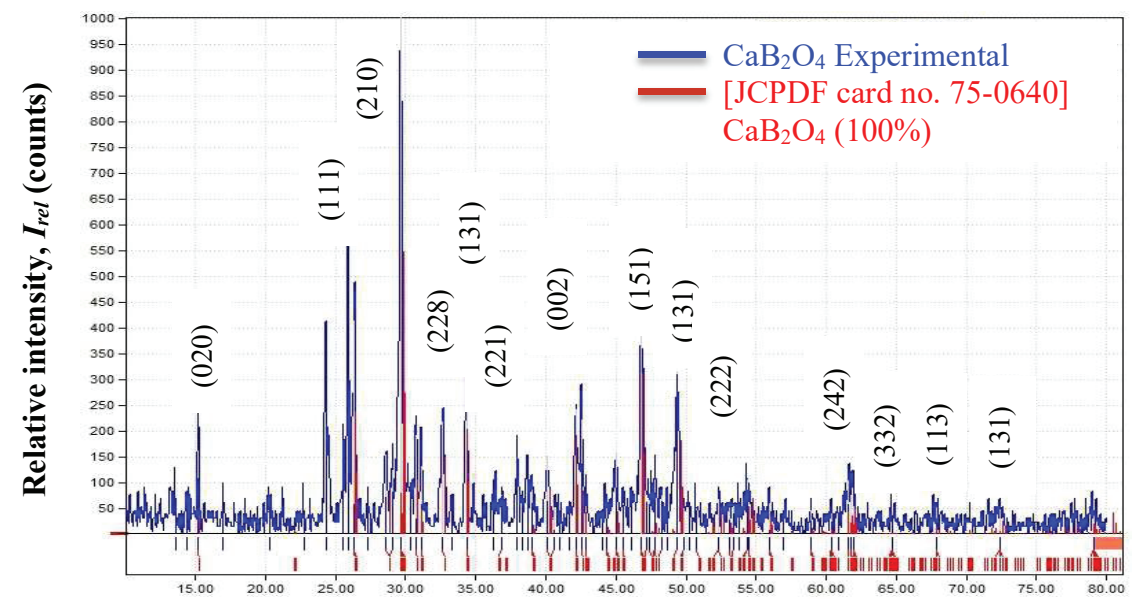

2 theta, $2 \theta\left({ }^{\circ}\right)$

Fig. 1. XRD patterns of $\mathrm{CaB}_{2} \mathrm{O}_{4}$ after heat treatment at temperature $900{ }^{\circ} \mathrm{C}$ for $1 \mathrm{~h}$. 


\subsection{Effect of annealing}

The optimum annealing procedures were investigated in order to determine the highest TL yield sensitivity of the prepared samples. Fig. 2 illustrates the TL intensity of nanocrystalline $\mathrm{CaB}_{2} \mathrm{O}_{4}$ powder before and after annealing at $300{ }^{\circ} \mathrm{C}$ and exposed to $100 \mathrm{~Gy}$ of cobalt- 60 irradiation. The intensity of nanocrystalline $\mathrm{CaB}_{2} \mathrm{O}_{4}$ powder after annealing process increases as compared to nanocrystalline $\mathrm{CaB}_{2} \mathrm{O}_{4}$ powder before annealing process from $1100 \mathrm{nA} \mathrm{g}^{-1}$ to $11000 \mathrm{nA} \mathrm{g}^{-1}$ at about $90 \%$. Thus, the annealing process is needed in every process of TLD used in order to increase accuracy and sensitivities of TL signal towards ionizing radiation.

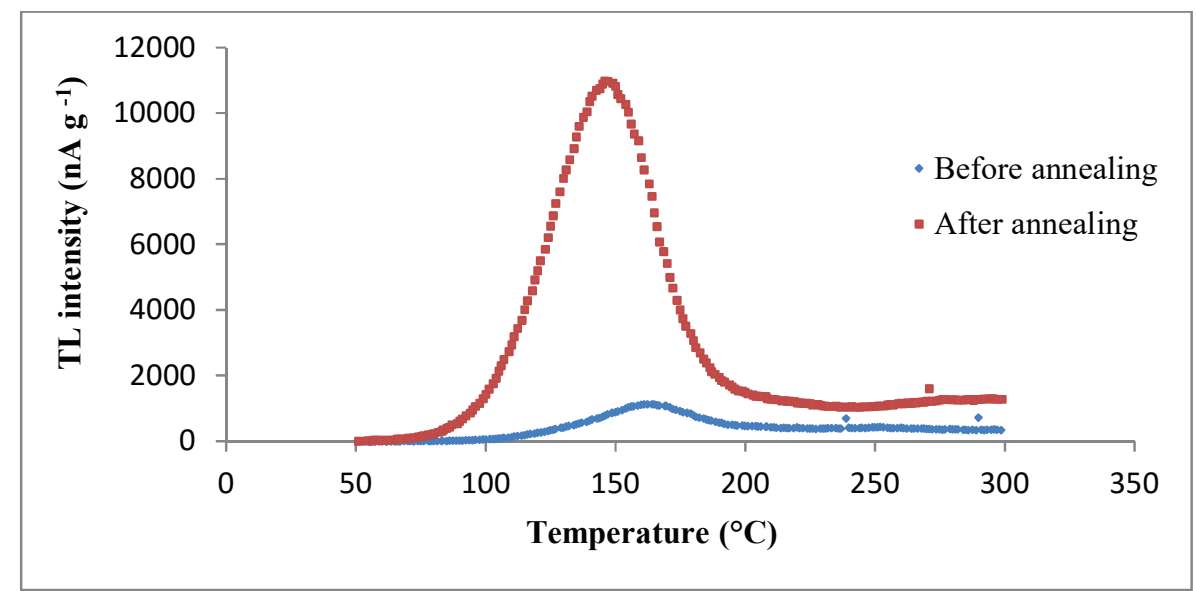

Fig. 2. TL intensity of nanocrystalline $\mathrm{CaB}_{2} \mathrm{O}_{4}$ powder before and after annealing at $300{ }^{\circ} \mathrm{C}$ and exposed to 100 Gy of cobalt-60 irradiation.

Some thermoluminescent material required a complex annealing procedure. Whether it requires a high temperature anneal or a low temperature anneal or both of them. The high temperature anneal is needed to clear the dosimetric traps of residual signal which may cause unwanted backgrounds during subsequent use of the dosimeters. Meanwhile, low temperature anneal is to stabilize and aggregate low temperature traps in order to enhance the sensitivity of the main dosimetry traps and to reduce losses of radiation induced signal due to thermal or optical fading during use [18].

Fig. 3 shows the TL intensity of nanocrystalline $\mathrm{CaB}_{2} \mathrm{O}_{4}$ powder for different annealing temperature at 1 hour. It displays a simple glow curve for all samples where these samples exhibit only one peak at around $150{ }^{\circ} \mathrm{C}$. The highest $\mathrm{TL}$ intensity was detected at $300{ }^{\circ} \mathrm{C}$ followed by $200{ }^{\circ} \mathrm{C}, 400{ }^{\circ} \mathrm{C}$ and $100{ }^{\circ} \mathrm{C}$. Fig. 4 indicates the TL response and standard deviation as a function of annealing temperatures from 100 to $400{ }^{\circ} \mathrm{C}$, which corresponds to data analysis from glow curves in Fig. 3. It can be seen that the highest TL response was obtained at $300{ }^{\circ} \mathrm{C}$ with the lowest standard deviation approximately $5 \%$. This means that, the annealing temperature of $300{ }^{\circ} \mathrm{C}$ is well sufficient to maximize the emptying of shallow traps and to boost electrons out of the traps. Since increased temperatures in the oven, resulting in increases thermal vibrations of the molecules and the rate of electron release. However, temperature above $300{ }^{\circ} \mathrm{C}$ causes irreversible damage to the material. Thus, changes in the molecular structure of the $\mathrm{CaB}_{2} \mathrm{O}_{4}$ nanocrystalline and reduce or induces changes to the number of electron traps. This would result in a loss of TL sensitivity as shown for annealing temperature at $400{ }^{\circ} \mathrm{C}$. Therefore, among the prepared samples, the sample at $300{ }^{\circ} \mathrm{C}$ was the best annealing temperature to produce the efficient thermoluminescence properties. Also, it is recommended that the maximum readout temperature in TLD reader is the same as the annealing temperature as the material become damaged when heated to temperatures above $300{ }^{\circ} \mathrm{C}$. 


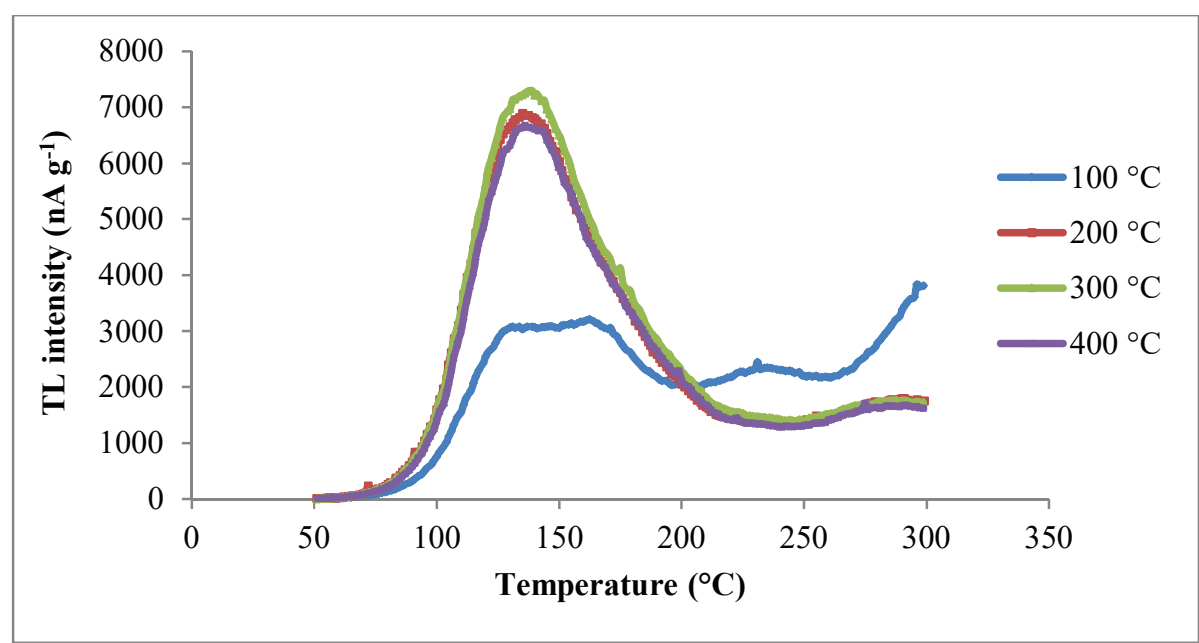

Fig. 3. TL intensity of nanocrystalline $\mathrm{CaB}_{2} \mathrm{O}_{4}$ powder under different annealing temperature for 1 hour after being exposed to 100 Gy of cobalt-60 irradiation.

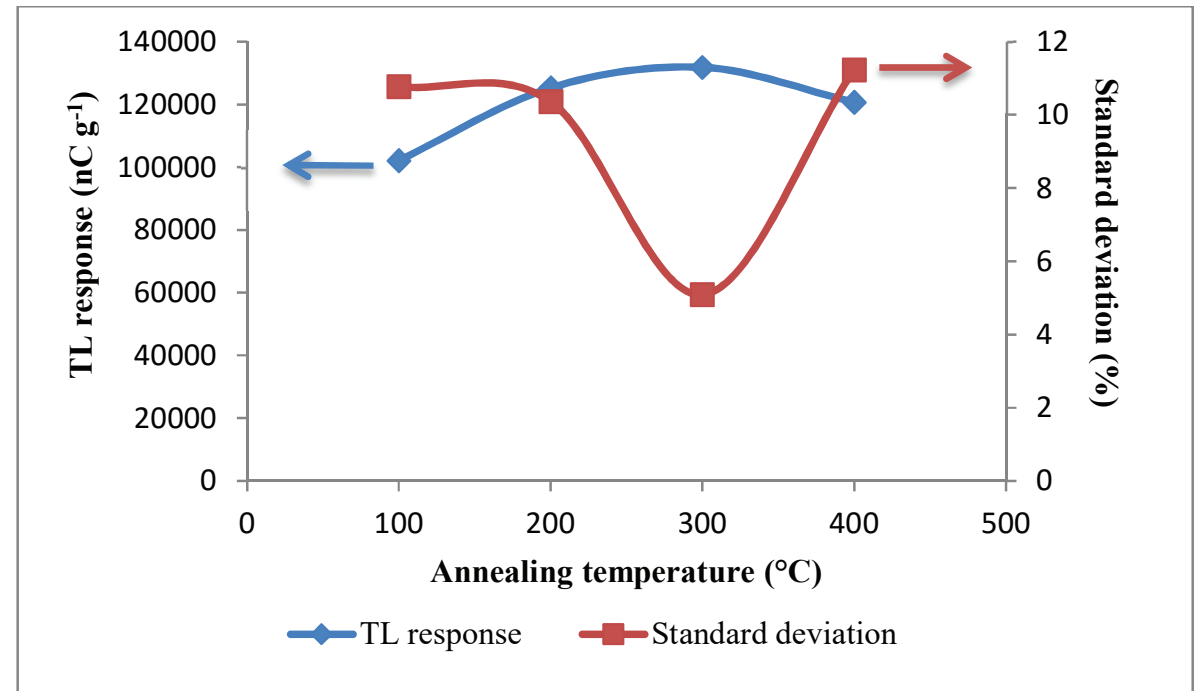

Fig. 4. TL response and the corresponding standard deviation as a function of annealing temperature at 1 hour for nanocrystalline $\mathrm{CaB}_{2} \mathrm{O}_{4}$ powder.

\subsection{Effect of heating rate}

The basic requirements for readout of thermoluminescence dosimeters (TLDs) is the heating rate in studying the dosimetric parameters. Fig. 5 shows the TL intensity of nanocrystalline $\mathrm{CaB}_{2} \mathrm{O}_{4}$ powder recorded at different linear heating rates between $1{ }^{\circ} \mathrm{C} \mathrm{s}^{-1}$ and $25^{\circ} \mathrm{C} \mathrm{s}^{-1}$ for $100 \mathrm{~Gy}$ of cobalt-60 exposure. As shown in the Fig. 5 , as the heating rate increases, the intensity increases and quickly decrease when the heating rate greater or equal to $20{ }^{\circ} \mathrm{C} \mathrm{s}^{-1}$ up to $25^{\circ} \mathrm{C} \mathrm{s}^{-1}$. A thermal quenching effect may be dominating in this portion of the curves where the heating rate $\geq 20^{\circ} \mathrm{C} \mathrm{s}^{-1}$ because the higher the heating rate, the less the probability that clusters will be formed [19]. The implication of formation of trap clusters instead of randomly distributed defects is that it may change the kinetics of trapping and recombination processes, thereby influencing the TL properties of a phosphor [20]. Because of the complex nature of the changes in the cluster formation with heating rate, hence, at some heating rate the cluster formation may be such that enhancement of thermoluminescence was greater than the total effect of reduction, suppression and thermal quenching effect on TL, while at the other heating rates it is vice versa. Also, in case of thermal quenching was present in the temperature range of a composite TL peak, a distortion may appear in the shape of the peak due to progressive quenching as the temperature increases during the heating [21]. Hence, the heating rate was one of the most important experimental parameters that adversely affects the intensities of glow peak of nanocrystalline $\mathrm{CaB}_{2} \mathrm{O}_{4}$ powder. 


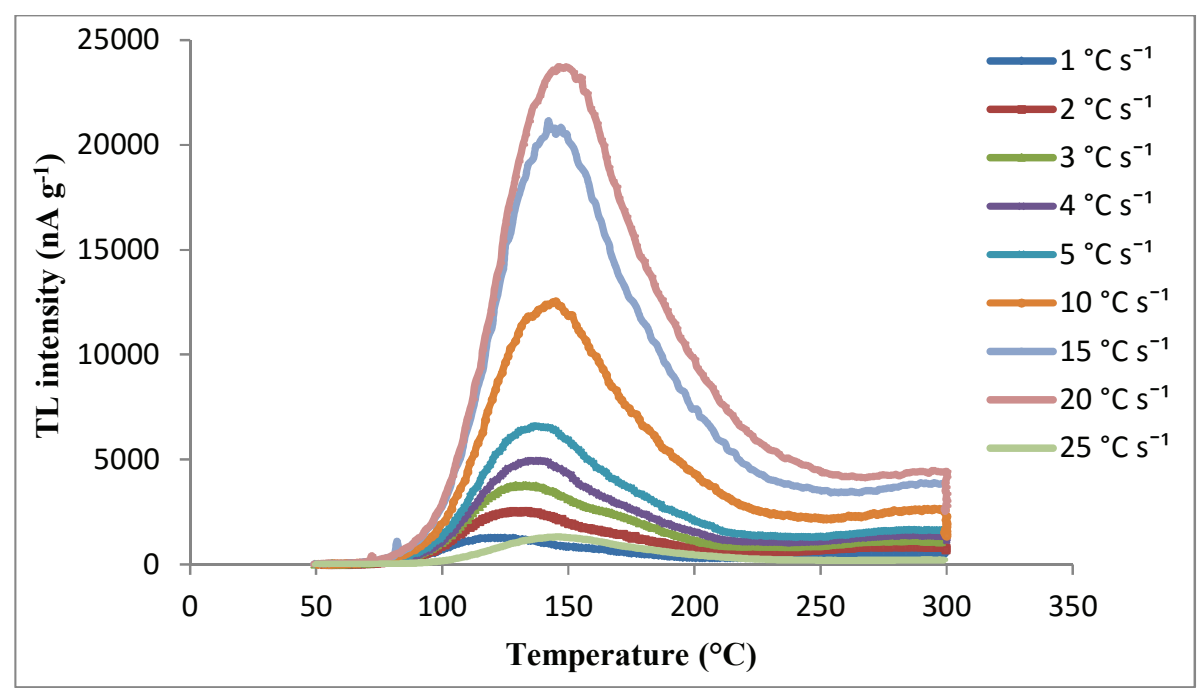

Fig. 5. TL intensity of nanocrystalline $\mathrm{CaB}_{2} \mathrm{O}_{4}$ powder under different heating rates after being exposed to 100 Gy of cobalt-60 irradiation.

Another important and most interesting result was observed in the behavior of the maximum glow peak temperature. Fig. 6 depicts the maximum glow peak temperature as a function of heating rate of the nanocrystalline $\mathrm{CaB}_{2} \mathrm{O}_{4}$ powder. There was a shift of the temperature at the maximum intensity of the glow peak $\left(T_{\max }\right)$ from low temperatures $121^{\circ} \mathrm{C}$ to high temperatures $145^{\circ} \mathrm{C}$ at heating rate $1{ }^{\circ} \mathrm{C} \mathrm{s}^{-1}$ to $10{ }^{\circ} \mathrm{C} \mathrm{s}^{-1}$. However, $T_{\max }$ start to fluctuate at a heating rate greater than $10^{\circ} \mathrm{C} \mathrm{s}^{-1}$ as shown in Fig. 6. As a result, the peak temperature was $142{ }^{\circ} \mathrm{C}, 150{ }^{\circ} \mathrm{C}$ and $146{ }^{\circ} \mathrm{C}$ for heating rate $15^{\circ} \mathrm{C} \mathrm{s}^{-1}, 20^{\circ} \mathrm{C} \mathrm{s}^{-1}$ and $25^{\circ} \mathrm{C} \mathrm{s}^{-1}$, respectively. Thermal fluctuation would allow repeated association and dissociation of such aggregates, a fraction of which might be capable of dissipating the stored energy reserves. If the fluctuations were not present, thus making TL intensity a function of heating rate [22]. A shift in $T_{\max }$ with the heating rate has an empirical explanation as proposed by Kitis et al. [23]. At a lower heating rate $\left(\beta_{1}\right)$, the time spent by the phosphor at a temperature $\left(T_{1}\right)$ is long enough, so that the amount of the thermal release of electrons depending on the half-life at this temperature could take place. As the heating rate increases to $\beta_{2}>\beta_{1}$ the time spent at the same temperature $T_{1}$ decreases and therefore the thermal release of electrons is also decreased. Hence a higher temperature $T_{2}$ is needed for the same amount of the thermal release to take place at $\beta_{2}$. In this way, the whole glow-peak is shifted to higher temperatures as the heating rate increases in a manner depending on the half-life and the time spent at each temperature. By contrast, a shift of $T_{\max }$ toward lower temperatures is due to thermal quenching studied previously by Akselrod et al. [24]. Therefore, there is a slight drop in $T_{\max }$ for $15^{\circ} \mathrm{C} \mathrm{s}^{-1}$ which shows the presence of the thermal quenching effect of thermoluminescence of nanocrystalline $\mathrm{CaB}_{2} \mathrm{O}_{4}$ powder. This property should be taken into consideration in TL investigations. Hereby, the selection of heating rate of $10{ }^{\circ} \mathrm{C} \mathrm{s}^{-1}$ has been made for obtaining the highest TL intensity based on the present results of TL intensity and maximum glow peak temperature for different heating rate.

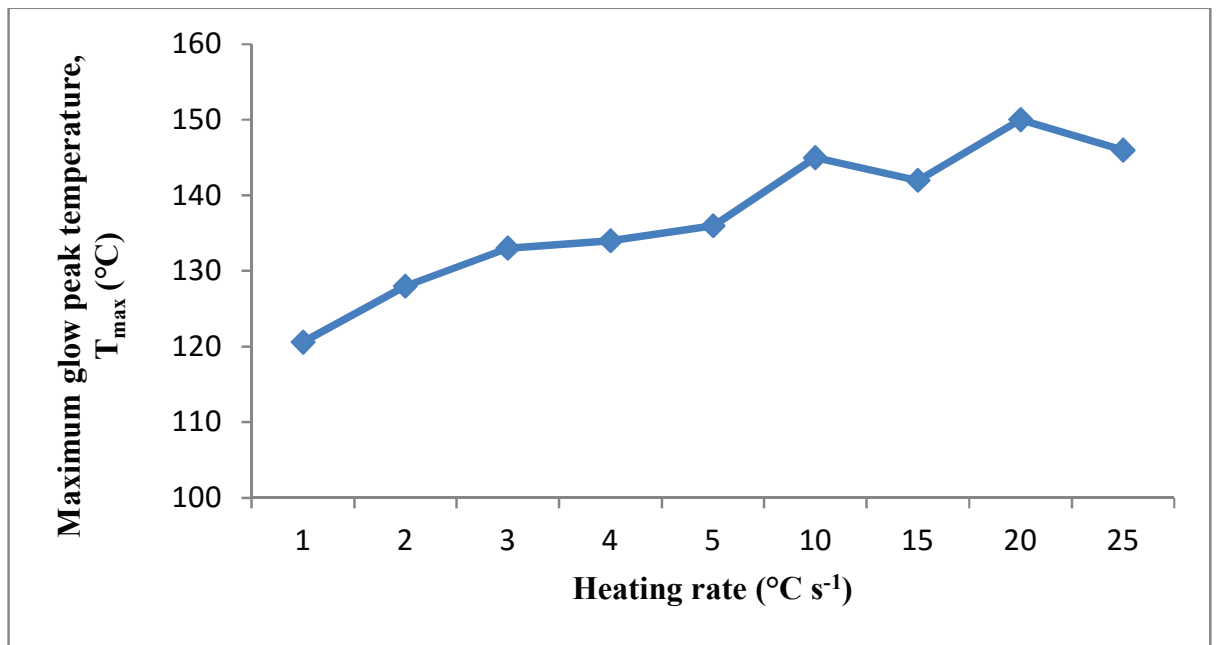

Fig. 6. Maximum glow peak temperature as a function of heating rate of nanocrystalline $\mathrm{CaB}_{2} \mathrm{O}_{4}$ powder for 100 Gy of cobalt- 60 exposure. 
The time temperature profile (TTP) in Table 1 lists the best read out parameters for nanocrystalline $\mathrm{CaB}_{2} \mathrm{O}_{4}$ powder. The heating rate that used was $10^{\circ} \mathrm{C} \mathrm{s}^{-1}$. This means that temperatures rise at $10^{\circ} \mathrm{C}$ starting from $50{ }^{\circ} \mathrm{C}$ for each second. Thus, $26.67 \mathrm{~s}$ was needed to reach the maximum temperature, which was $300^{\circ} \mathrm{C}$. Preheat time was $0 \mathrm{~s}$ due to no low temperature peak detected to be eliminated. Meanwhile, for anneal time was $0 \mathrm{~s}$ because the annealing procedure only carried out in TLD oven. It must be noted that the annealing procedures can be carried out in the TLD reader itself. However, its efficiency is very low when high dose values are involved. The in-reader annealing procedure should be used only if the dose received by the dosimeter is lower than $10 \mathrm{mGy}$ to $20 \mathrm{mGy}$ [25]. Hence, for this reason, the annealing procedure for nanocrystalline $\mathrm{CaB}_{2} \mathrm{O}_{4}$ powder must be performed in an oven.

Table 1. Time temperature profile (TTP).

\begin{tabular}{|c|c|}
\hline Parameter & Value \\
\hline Preheat temperature & $50{ }^{\circ} \mathrm{C}$ \\
\hline Preheat time & $0 \mathrm{~s}$ \\
\hline Heating rate & $10^{\circ} \mathrm{C} \mathrm{s}^{-1}$ \\
\hline $\begin{array}{c}\text { Maximum } \\
\text { temperature }\end{array}$ & $300^{\circ} \mathrm{C}$ \\
\hline Acquire time & $26.67 \mathrm{~s}$ \\
\hline Anneal temperature & $300^{\circ} \mathrm{C}$ \\
\hline Anneal time & $0 \mathrm{~s}$ \\
\hline
\end{tabular}

\section{Conclusion}

Nanocrystalline $\mathrm{CaB}_{2} \mathrm{O}_{4}$ powder was successfully prepared using the solution combustion method. The XRD result confirmed the $\mathrm{CaB}_{2} \mathrm{O}_{4}$ phase with particle size at about $27 \mathrm{~nm}$ by using Debye-Scherrer formula. $\mathrm{CaB}_{2} \mathrm{O}_{4}$ has a simple glow curve with only one and a well defined peak at around $150{ }^{\circ} \mathrm{C}$. TL intensity was higher after annealing the material before irradiation which indicated the importance of annealing. Annealing temperature and heating rate profiles strongly influenced TL properties of nanocrystalline $\mathrm{CaB}_{2} \mathrm{O}_{4}$ powder. Annealing temperature above $300{ }^{\circ} \mathrm{C}$ causes damage to the material which result in a loss of TL sensitivity. A shift of $T_{\max }$ from high temperatures to lower temperatures suggests the presence of thermal quenching at a heating rate greater than $10{ }^{\circ} \mathrm{C} \mathrm{s}^{-1}$. As a result of this study, it is recommended to use an annealing temperature at $300{ }^{\circ} \mathrm{C}$ for one hour and the heating rate of $10{ }^{\circ} \mathrm{C} \mathrm{s}^{-1}$ to produce high TL intensity. In order to have a tenable explanation for the variations it will require a more detailed experiment, however, the variations will be due to interplay of more than one phenomenon. This is because a single model may not be sufficient to explain the observed variations. The detailed measurements will be carried out on nanocrystalline $\mathrm{CaB}_{2} \mathrm{O}_{4}$ powder in further studies to get significant information about the kinetics involved in the process that is obtained from TL glow curve and serves as a tool for evaluating the various TL parameters like activation energy $(E)$ and frequency factor $(s)$.

Acknowledgements The authors would like to thank the Ministry of Education (MOE), Malaysia and Universiti Teknologi Malaysia for providing research grants and facilities. Our appreciation also goes to Mr. Ahmad Takim bin Saring from School of Applied Physics, Faculty of Science and Technology, Universiti Kebangsaan Malaysia, 43600 UKM Bangi, Selangor Darul Ehsan, Malaysia for performing cobalt-60 irradiation.

\section{References}

1. J. Izewska, G. Azangwe, P. Bera, SSDL Newsletter, 58, 17-23 (2010)

2. S. W. S. McKeever and M. Moscovitch, Rad. Prot. Dos., 104, 263-270 (2003)

3. B. F. Wall, C. M. H. Driscoll, J. C. Strong, E. S. Fisher, Phys. Med. Biol., 27 (8), 1023-1034 (1982)

4. V. S. Kortov, Radiat. Meas., 45, 3-6 (2010)

5. N. Salah, Z. H. Khan, S. S. Habib, Nucl. Instrum. Methods Phys. Res., 269, 401-404 (2011)

6. L. Singh, V. Chopra, S.P. Lochab, J. Lumin., 131, 1177-1183 (2011)

7. P. D. Sahare, J. S. Bakare, S. D. Dhole, N. B. Ingale, A. A. Rupasov, J. Lumin., 130, 258-265 (2010)

8. M. E. Haghiri, E. Saion, N. Soltani, W. S. Wan Abdullah, M. Navasery, K. R. E. Saraee, N. Deyhimi, J. Alloys Compd., 582, 392-397 (2014)

9. S. Gowda, S. Krishnaveni, T. Yashoda, T. K. Umesh, R. Gowda, PRAMANA- J. Phys., 63, 529-541 (2004)

10. M. Santiago, C. Grasseli, E. Caselli, M. Lester, A. Lava, F. Spano, Phys. Status Solidi (A), 185 (2), 285-289 (2001)

11. Y. Fujimoto, T. Yanagida, M. Koshimizu, K. Asai, Opt. Mater., 41, 49-52 (2015)

12. E. Nakazawa, T. Mochida, J. Lumin., 236, 72-74 (1997)

13. S. T. Aruna, A. S. Mukasyan, Curr. Opin. Solid State Mater. Sci., 12, 44-50 (2008)

14. J. H. Bai, J. C. Liu, Sci. Sinter., 42, 133-141 (2010) 
15. J. I. Langford, A. J. C. Wilson, J. Appl. Cryst., 11, 102-113 (1978)

16. J. Huang, L. Zhou, Q. Pang, F. Gong, J. Sun, W. Wang, J. Lumin. , 24(6), 363-366 (2009)

17. X. Yang, L. Zhang, X. Chen, X. Sun, G. Yang, X. Guo, H. Yang, C. Gao, Z. Gou, J. Non-Cryst. Solids., 358, 1171-1179 (2012)

18. C. Furetta, Handbook of Thermoluminescence, World Scientific, Singapore, 8-10 (2003)

19. N. A. Spooner, A. D. Franklin, Radiat. Meas. , 35, 59-66 (2002)

20. A. Mandowski, , J., Swiatek, J. Phys. III France, 7, 2275-2280 (1997)

21. C. M. Sunta, V. N. Bapat, PACT, 6, 252 (1982)

22. S. K. Bhattacharjee, Curr. Sci., 84 (11), 1419-1427 (2003)

23. G, Kitis, M. Spiropulu, J. Papadopoulos, S. Charalambous, Nucl Instrum Methods Phys Res, 73, 367-72 (1993)

24. M. S. Akselrod, N. Agersnap Larsen, V. Whitley, S. W. S. McKeever, J. Appl. Phys., 84, 3364 (1998) 